\title{
New Insights into Thyroid Stem Cells
}

\author{
Reigh-Yi Lin \\ Division of Endocrinology, Diabetes, and Bone Diseases, Department of Medicine, Mount Sinai \\ School of Medicine, New York, New York.
}

\begin{abstract}
Stem cells exhibit an extraordinary ability for self-renewal. They also give rise to many specialized cells. The potential of stem cells in regenerative medicine, developmental biology, and drug discovery has been well documented. Although advances in stem cell science have raised broad ethical concerns, it is clear that stem cell technology has revolutionized our thinking in modern biology and medicine and provided the basis for understanding many of the mechanisms controlling basic biological processes and disease mechanisms. This review details the nascent field of thyroid stem cell research, exploring the current status of thyroid stem cell differentiation from the perspectives of both developmental biology and cell replacement therapy. It highlights successes to date in the generation of thyroid follicular cells from embryonic stem cells in the laboratory and the identification and characterization of adult stem cells from human thyroid glands and thyroid cancers. Finally, it outlines future challenges with a focus on potential stem cell therapy for thyroid patients.
\end{abstract}

\section{Introduction}

The potential of stem cells in regenerative medicine, developmental biology, and drug discovery has been documented in ever-increasing number of publications. Although much research has focused on the differentiation of clinically significant pancreatic $\beta$ cells, hepatocytes, cardio-myocytes, and neurons, the understanding of thyroid stem cell biology has also made significant strides during the past few years. This review details the current status of thyroid stem cell biology, from the perspectives of both developmental biology and cell replacement therapy. The first sections of the review highlight successes to date in the generation of thyroid follicular cells from embryonic stem cells, and the evidence for the presence of adult stem cells in human thyroid glands and cancer stem cells in thyroid cancers. The final section of the review outlines future challenges facing successful stem cell therapy for thyroid patients.

\section{What Are Stem Cells and Why Are They Important?}

Stem cells are cells that have the ability to divide indefinitely in culture and also to give rise to many different specialized cell types. In general, stem cells are broadly divided into three groups: embryonic stem cells, fetal stem cells, and adult stem cells. Embryonic stem cells are primitive or undifferentiated cells derived from the inner cell mass of blastocyst-stage embryos $(1,2)$. They are remarkably plastic. They divide indefinitely in laboratory culture dishes and can differentiate into all cell types in the body when exposed to the appropriate growth factors or hormones. Fetal stem cells are found in all rapidly growing fetal organs and tissues. Adult, or somatic, stem cells are unspecialized cells that can both renew themselves and yield all

\footnotetext{
(C) Mary Ann Liebert, Inc.
}

Address reprint requests to: Reigh-Yi Lin, Ph.D., Department of Medicine, Mount Sinai School of Medicine, One Gustave L. Levy Place, Box 1055, New York, NY 10029, E-mail: E-mail: reigh-yi.lin@mssm.edu. 
specialized cell types of the tissue from which they originate. Hair cells, skin cells, and male germ cells - all capable of routine self-renewal—are examples of adult stem cells. Another example is bone marrow stem cells.

Stem cells are also classified as totipotent, pluripotent, or multipotent depending on how many different cell types they can generate. A totipotent stem cell can give rise to all the cell types in an entire body as well as the cell types that make up the extraembryonic tissues, such as the amnion, the chorion, and the placenta. In contrast, a pluripotent stem cell, such as an embryonic stem cell, can give rise to all of the cell types in the body but they cannot make extraembryonic tissues. It is important to understand that, although scientists believe that some adult stem cells from one tissue can develop into cells of another tissue, so far no adult stem cell has been shown in culture to be pluripotent. Therefore, the developmental potential of adult stem cells is limited. Finally, a multipotent stem cell is a stem cell that has the ability to develop into more than one cell type. An example is blood stem cells, which can give rise to both red and white blood cells.

Stem cell research holds great promise for many areas of biology and medicine. The possibility of using stem cells as a novel and unlimited source of cells for cell-based therapy for a broad spectrum of debilitating diseases has received much recent attention. Much current research is focused on replacing bone marrow after leukemia or chemotherapy, replacing dopaminesecreting neurons in the brain of a person with Parkinson's disease, infusing cardiac muscle cells in a heart damaged by myocardial infarction, and transplanting insulin-producing pancreatic $\beta$ cells in diabetic patients. In addition to cell replacement therapy, the ability to access cell populations representing the early stages of embryonic stem cell differentiation provides an exciting and unparalleled opportunity to model embryonic development and to conduct experiments that would not be possible in human embryos. Understanding the molecular and genetic pathways of normal early development may one day help physicians to both prevent and treat birth defects, for example. Furthermore, the analysis of human embryonic stem cells derived from patients with specific genetic disorders could provide novel insights into the disease process and could be used to test new therapeutic approaches. Finally, the ability to genetically engineer stem cells may allow clinicians to test the effect of current drugs and to develop clinically relevant screening assays that would not otherwise be possible.

\section{In Vitro Derivation of Functional Thyroid Follicular Cells from Embryonic Stem Cells: Are We There Yet?}

The discovery of pluripotent mouse embryonic stem cells more than 20 years ago $(1,2)$ sparked a period of intense investigation. These cells provided the basis for in vitro models of early mammalian embryonic development and represented a new source of cells for cell-based therapy. When cultured with leukemia inhibitory factor, mouse embryonic stem cells can be maintained in an undifferentiated state for prolonged periods. Upon withdrawal of leukemia inhibitory factor, these cells spontaneously differentiate to form three-dimensional cellular aggregates or embryoid bodies that contain elements of all three primary embryonic germ layers: ectoderm, mesoderm, and endoderm (3). The embryoid body recapitulates stages of early embryogenesis through gastrulation, including the formation of postimplantation embryonic tissues. By manipulating the culture conditions under which embryonic stem cells differentiate, embryoid bodies can be further coaxed to differentiate into cells of all lineages. To date, embryonic stem cell-derived hematopoietic, cardiac, neuronal, and pancreatic $\beta$ cells, as well as hepatocytes, have been successfully generated and transplanted into recipient animals (4-13).

Several years ago we established culture conditions that allow the derivation of thyrocyte-like cells from mouse wild-type CCE embryonic stem cells. The protocol includes a 2-week treatment with thyroid-stimulating hormone (TSH), the main regulator of the thyroid gland 
$(14,15)$. We showed that 6-day-old embryoid bodies derived from embryonic stem cells express genes traditionally associated with thyroid follicular cells: PAX8, the $\mathrm{Na}^{+} / \mathrm{I}^{-}$symporter, thyroglobulin, thyroperoxidase, and the TSH receptor (14). The embryoid bodies also exhibited thyroid-specific function, such as cAMP generation by TSH (14). Together, these attributes suggest that thyrocyte development is recapitulated in this embryonic stem cell model system. We next examined ways to enrich the proportion of thyroid cells obtained during embryonic stem cell differentiation. We generated an embryonic stem cell line carrying an enhanced green fluorescent protein-neomycin-resistant (GFP-Neor) cassette under the control of the TSH receptor promoter (16). This embryonic stem cell line allowed us to track thyroid-specific development by following GFP expression during embryonic stem cell differentiation in vitro. We found that the appearance of GFP-positive cells was dependent on the formation of embryonic stem cell-derived embryoid bodies and that the proportion of GFP-positive cells was greatly enhanced by TSH treatment during the first 2-4 days of differentiation. These highly enriched embryonic stem cell-derived GFP-positive cells formed thyroid follicle-like cell clusters on Matrigel in a serum-free medium supplemented with TSH (17). Immunofluorescent studies confirmed the colocalization of TSH receptor with the $\mathrm{Na}^{+} / \mathrm{I}^{-}$ symporter in the clusters and indicated that the $\mathrm{Na}^{+} / \mathrm{I}^{-}$symporter was expressed exclusively in the plasma membrane. In addition, $\mathrm{I}^{-}$uptake activity was observed in these cells (17). Our methods marked the first successful derivation of thyroid follicular cells from embryonic stem cells and highlighted their potential in the study of genes and factors involved in the specification of thyroid lineage. However, there are two major problems with this system. First, the differentiated cell populations were still heterogeneous; the percentage of differentiated thyroid cells was low (less than 1\%). Second, as with many other embryonic stem cell-derived cell-specific lineages, characterization of lineage-committed pure stem cell populations is still problematic. It is not yet possible in our model to make perfect thyroid cells. For example, although we demonstrated that embryonic stem cell-derived thyroid follicular cells express several thyroid markers, we were not able to detect thyroglobulin expression in these cells. Although the molecular trigger for thyroglobulin production remains to be determined, this discrepancy supports the notion that TSH exposure is not sufficient for thyroglobulin synthesis and suggests that additional factors must be needed for thyroglobulin expression and thyroid hormone synthesis. Embryonic stem cells clearly provide a useful new model for the investigation of these and other pertinent signaling pathways.

Because embryonic stem cell differentiation varies in some respects between species, findings in mice will need to be confirmed in human embryonic stem cells. Human embryonic stem cells were first isolated in 1998 (18), almost 17 years after the discovery of their mouse counterparts. This delay was in part due to the additional technical challenges involved in the isolation of human embryonic stem cells and to ethical concerns and legal restrictions regarding the destruction of human embryos. Nonetheless, the current availability of certain human embryonic stem cell lines brings possible cell replacement therapies one step closer to reality. At present, there are some protocols that provide relatively easy maintenance of human embryonic stem cell populations. Recently, D'Amour et al. (19) demonstrated that activin A, a member of the TGF $\beta$ family, stimulates the differentiation of up to $80 \%$ of human embryonic stem cells into definitive endoderm cells. Their data suggested that the formation of endoderm from differentiating human embryonic stem cell cultures is similar to endoderm differentiation occurring during vertebrate gastrulation in vivo. Subsequent transplantation of these human embryonic stem cell-derived endoderm cells under the renal capsule caused them to further differentiate into more-mature cells of endodermal organs (19). Several other groups have reported an ability to generate a variety of endoderm-derived cells from differentiating human embryonic stem cells, including insulin-expressing pancreatic $\beta$ cells and hepatocytes $(7,10$, 20). Given the fact that thyroid follicular cells also arise from the endoderm during vertebrate development, it is likely that similar strategies could be used to stimulate their differentiation from human embryonic stem cells. Although the precise culture conditions necessary have not 
yet been determined, the identification of unique thyroid-specific differentiation profiles in embryonic stem cell cultures will doubtless help unravel the mechanisms of thyrocyte differentiation.

\section{Evidence for Adult Stem Cells in Human Thyroid Glands}

Adult stem cells have been detected in human bone marrow, liver, pancreas, and brain. Thomas et al. (21) recently also used RT-PCR, flow cytometry, and immunofluorescence to detect the expression of the stem cell marker Oct- 4 and the endodermal markers GATA-4 and HNF4 $\alpha$ in primary cultures isolated from human goiters. They also detected expression of Oct-4, but not GATA-4, in some thyroid carcinoma cell lines (21). Their findings suggest the presence of adult stem and precursor cells of endodermal origin in the human thyroid gland. It will be interesting to determine whether these putative stem or progenitor cells are able to self-renew and to differentiate into thyrocytes or various other cell lineages. Furthermore, adult thyroid stem cells must by their nature respond to different cellular signals than do embryonic stem cells. Understanding the gene expression programs that orchestrate these differences will provide valuable information necessary to assess whether thyroid stem cells may be a useful therapy for hypothyroidism.

\section{The Search for Thyroid Cancer Stem Cells: Do They Exist?}

Thyroid cancer is the most common endocrine malignancy. The American Cancer Society estimates that there will be $\sim 33,550$ new cases of thyroid cancer in the United States in 2007 (22). While $80-85 \%$ of thyroid carcinomas are well differentiated and most have a favorable prognosis, anaplastic thyroid cancer appears almost fatal in origin and patients have a mean survival of only 7.2 months. Despite surgery, chemotherapy, and radiotherapy, few patients with anaplastic thyroid carcinoma live more than 1 year follow-up diagnosis. Anaplastic thyroid cancer is characterized by marked epithelial mesenchymal transition. Although histopathological evidence suggests that anaplastic thyroid cancer may arise from dedifferentiation of well-differentiated thyroid tumors, it has not yet been possible to induce thyroid cells to dedifferentiate in culture. An alternative explanation for the derivation of anaplastic thyroid carcinoma may lie in the recent discovery of cancer stem cells, which can self-renew and give rise to phenotypically diverse cancer cells with varying potentials for proliferation and new tumor formation. Cancer stem cells have been isolated from leukemias, breast cancers, lung cancers, pancreatic cancers, prostate cancers, and tumors of the central nervous system (23-28). Several stem cell models for thyroid cancer have also been postulated $(29,30)$. If the existence of cancer stem cells were confirmed in certain thyroid cancers, the finding would have significant clinical implications for the way we diagnose and treat thyroid cancer patients. Mitsutake et al. (31) were the first to isolate a small number (less than $0.25 \%$ of the total population) of side population cells from several thyroid cancer cell lines: two anaplastic cancer cell lines, one papillary cancer, and one follicular cancer. Side population cells, which have now been reported in a variety of established cancer cell lines, are highly enriched for adult stem cells (32-34). However, both side population and nonside population cells derived from these thyroid cancer cell lines can form tumors when injected into nude mice (31). This finding suggests that cancer stem cells are not exclusive to or identical to side population cells.

In another study, Cameselle-Teijeiro et al. (35) reported that the main cells of solid cell nests of the human thyroid gland have some stem cell properties, including a capacity for selfrenewal and an ability to differentiate into more than one cell type. However, these cells do not express terminal thyroid differentiation markers such as thyroglobulin and calcitonin. The researchers suggested a possible link between papillary oncogenesis and the existence of stemlike cells in the adult thyroid. This view is shared by Burstein et al. (36), who proposed a role 
for p63 in a stem cell model of papillary carcinoma. p63, a p53 homolog, has been detected via immunohistochemistry in basal and parabasal squamous cells and in bronchial basal cells of squamous and bronchial epithelia $(37,38)$. These investigators showed that p63 expression in solid cell nests and papillary thyroid carcinoma cells closely resembles the stem cellassociated p63 staining patterns reported in squamous and bronchial epithelia. They therefore proposed that the cellular origin of papillary carcinoma is "an undifferentiated, p63-positive embryonic remnant with pluripotent stem cell activity." While this hypothesis is interesting, it is again important to note that so far no adult stem cells have been shown to be pluripotent. It is possible, however, that these cells exist as a small proportion of the adult stem cells in the human thyroid. Further research is also needed to determine whether these p63-positive cells actually play a role in the tumorigenic process. It is becoming increasingly clear that many cancers are the result of stem cell disorders. Identification of a stem cell population in thyroid carcinogenesis will enhance understanding of the oncogenic process and provide new prognostic markers to guide therapy.

\section{Stem Cell Therapy for Thyroid Patients: Do We Need to Make Thyroid Cells?}

Exploration of the therapeutic potential of stem cell therapy for cell replacement is in its infancy. Recent advances in stem cell biology have raised the possibility of therapy for type 1 diabetes, Parkinson's disease, and myocardial infarction. However, the availability of an effective, economical, standardized, and well-tolerated hormone replacement therapy for hypothyroidism may render stem cell-based therapies unnecessary in most cases. If cell replacement therapy were to be used for transplantation therapy, however, certain minimum requirements must be met. First, a precursor population of embryonic or adult stem cells must be identified that is capable of in vitro expansion into large numbers of mature, replacement thyroid cells. Second, these replacement cells must be able to synthesize thyroglobulin, transport iodide, iodinate thyroglobulin, and store and release thyroid hormones in a physiologically appropriate manner. Third, it must be possible to tightly control the proliferative capacity of the replacement cells to avoid development of hyperthyroidism in vivo. Although this is not a problem when transplanting nonproliferating primary thyroid cells, the situation is likely to be different when transplanting embryonic stem cells with considerable proliferative ability. Finally and most importantly, the transplanted cells must have some way to escape destruction by the recipient's immune system. This is a major concern in patients with thyroid autoimmunity disorders, such as Hashimoto's thyroiditis. It is possible that the immune system response could be bypassed and immunosuppression avoided by genetically engineered thyroglobulin-producing cells that are developmentally and immunologically distinct from primary thyroid cells.

Although much research has focused on the generation of cardiomyocytes, as well as neuronal and pancreatic $\beta$ cells, an efficient and reproducible protocol to induce the differentiation of stem cells into functional thyroid follicular cells suitable for transplantation has yet to be reported. It is now clear that a variety of tissues harbor stem or progenitor cells that, if isolated and enriched, would be a potential source of cells for transplantation. The thyroid is another obvious source. A number of studies have suggested the existence of stem cells within the thyroid. However, to date, there is no convincing evidence that thyroglobulin-producing cells derived from stem cells can be expanded in vitro to clinically useful numbers.

\section{Conclusion}

In this paper, I tried to synthesize published studies and personal views on the subject of thyroid stem cells. I believe that our ability to prospectively identify, isolate, and study thyroid stem cells under both normal and malignant conditions will significantly further our capability to diagnose and treat our patients with thyroid disease. 


\section{Acknowledgments}

I would like to thank Drs. Terry Davies and Gordon Keller and members of their laboratories for excellent technical assistance. Special thanks to Dr. Richard Haber for his valuable comments on this manuscript. RYL is supported by a grant from the National Institutes of Health (R01 DK068057).

The author declares that there is no conflict of interest that would prejudice the impartiality of this scientific work.

\section{References}

1. Martin GR. Isolation of a pluripotent cell line from early mouse embryos cultured in medium conditioned by terato-carcinoma stem cells. Proc Natl Acad Sci USA 1981;78:7634-7638. [PubMed: 6950406]

2. Evans MJ, Kaufman MH. Establishment in culture of pluripotential cells from mouse embryos. Nature 1981;292:154-156. [PubMed: 7242681]

3. Itskovitz-Eldor J, Schuldiner M, Karsenti D, Eden A, Yanuka O, Amit M, Soreq H, Benvenisty N. Differentiation of human embryonic stem cells into embryoid bodies compromising the three embryonic germ layers. Mol Med 2000;6:88-95. [PubMed: 10859025]

4. Boheler KR, Czyz J, Tweedie D, Yang HT, Anisimov SV, Wobus AM. Differentiation of pluripotent embryonic stem cells into cardiomyocytes. Circ Res 2002;91:189-201. [PubMed: 12169644]

5. Brustle O, Jones KN, Learish RD, Karram K, Choudhary K, Wiestler OD, Duncan ID, McKay RD. Embryonic stem cell-derived glial precursors: a source of myelinating transplants. Science 1999;285:754-756. [PubMed: 10427001]

6. Lumelsky N, Blondel O, Laeng P, Velasco I, Ravin R, McKay R. Differentiation of embryonic stem cells to insulin-secreting structures similar to pancreatic islets. Science 2001;292:1389-1394. [PubMed: 11326082]

7. Jiang W, Shi Y, Zhao D, Chen S, Yong J, Zhang J, Qing T, Sun X, Zhang P, Ding M, Li D, Deng H. In vitro derivation of functional insulin-producing cells from human embryonic stem cells. Cell Res 2007;17:333-344. [PubMed: 17426693]

8. Keller G, Snodgrass HR. Human embryonic stem cells: the future is now. Nat Med 1999;5:151-152. [PubMed: 9930859]

9. Ku HT, Zhang N, Kubo A, O’Connor R, Mao M, Keller G, Bromberg JS. Committing embryonic stem cells to early endocrine pancreas in vitro. Stem Cells 2004;22:1205-1217. [PubMed: 15579640]

10. Kubo A, Shinozaki K, Shannon JM, Kouskoff V, Kennedy M, Woo S, Fehling HJ, Keller G. Development of definitive endoderm from embryonic stem cells in culture. Development 2004;131:1651-1662. [PubMed: 14998924]

11. Ogawa S, Tagawa Y, Kamiyoshi A, Suzuki A, Nakayama J, Hashikura Y, Miyagawa S. Crucial roles of mesodermal cell lineages in a murine embryonic stem cell-derived in vitro liver organogenesis system. Stem Cells 2005;23:903-913. [PubMed: 16043458]

12. Shirahashi H, Wu J, Yamamoto N, Catana A, Wege H, Wager B, Okita K, Zern MA. Differentiation of human and mouse embryonic stem cells along a hepatocyte lineage. Cell Transplant 2004;13:197211. [PubMed: 15191158]

13. Foshay K, Rodriguez G, Hoel B, Narayan J, Gallicano GI. JAK2/STAT3 directs cardiomyogenesis within murine embryonic stem cells in vitro. Stem Cells 2005;23:530-543. [PubMed: 15790774]

14. Lin RY, Kubo A, Keller GM, Davies TF. Committing embryonic stem cells to differentiate into thyrocyte-like cells in vitro. Endocrinology 2003;144:2644-2649. [PubMed: 12746328]

15. Lin RY, Davies TF. Derivation and characterization of thyrocyte-like cells from embryonic stem cells in vitro. Methods Mol Biol 2006;330:249-261. [PubMed: 16846029]

16. Marians RC, Ng L, Blair HC, Unger P, Graves PN, Davies TF. Defining thyrotropin-dependent and -independent steps of thyroid hormone synthesis by using thyrotropin receptor-null mice. Proc Natl Acad Sci USA 2002;99:15776-15781. [PubMed: 12432094]

17. Arufe MC, Lu M, Kubo A, Keller G, Davies TF, Lin RY. Directed differentiation of mouse embryonic stem cells into thyroid follicular cells. Endocrinology 2006;147:3007-3015. [PubMed: 16497809] 
18. Thomson JA, Itskovitz-Eldor J, Shapiro SS, Waknitz MA, Swiergiel JJ, Marshall VS, Jones JM. Embryonic stem cell lines derived from human blastocysts. Science 1998;282:1145-1147. [PubMed: 9804556]

19. D'Amour KA, Agulnick AD, Eliazer S, Kelly OG, Kroon E, Baetge EE. Efficient differentiation of human embryonic stem cells to definitive endoderm. Nat Biotechnol 2005;23:1534-1541. [PubMed: 16258519]

20. Mfopou JK, De Groote V, Xu X, Heimberg H, Bouwens L. Sonic Hedgehog and other soluble factors from differentiating embryoid bodies inhibit pancreas development. Stem Cells 2007;25:1156-1165. [PubMed: 17272496]

21. Thomas T, Nowka K, Lan L, Derwahl M. Expression of endoderm stem cell markers: evidence for the presence of adult stem cells in human thyroid glands. Thyroid 2006;16:537-544. [PubMed: 16839255]

22. American Cancer Society: cancer facts and figures 2007. http://www.cancer.org/docroot/STT/content/STT_1x_Cancer_Facts_Figures_2007.asp

23. Bonnet D, Dick JE. Human acute myeloid leukemia is organized as a hierarchy that originates from a primitive hematopoietic cell. Nat Med 1997;3:730-737. [PubMed: 9212098]

24. Lapidot T, Sirard C, Vormoor J, Murdoch B, Hoang T, Caceres-Cortes J, Minden M, Paterson B, Caligiuri MA, Dick JE. A cell initiating human acute myeloid leukaemia after transplantation into SCID mice. Nature 1994;367:645-648. [PubMed: 7509044]

25. Kim CF, Jackson EL, Woolfenden AE, Lawrence S, Babar I, Vogel S, Crowley D, Bronson RT, Jacks T. Identification of bronchioalveolar stem cells in normal lung and lung cancer. Cell 2005;121:823835. [PubMed: 15960971]

26. Meszoely IM, Means AL, Scoggins CR, Leach SD. Developmental aspects of early pancreatic cancer. Cancer J 2001;7:242-250. [PubMed: 11561600]

27. Hudson DL. Epithelial stem cells in human prostate growth and disease. Prostate Cancer Prostatic Dis 2004;7:188-194. [PubMed: 15289813]

28. Huntly BJ, Gilliland DG. Leukaemia stem cells and the evolution of cancer-stem-cell research. Nat Rev Cancer 2005;5:311-321. [PubMed: 15803157]

29. Takano T, Amino N. Fetal cell carcinogenesis: a new hypothesis for better understanding of thyroid carcinoma. Thyroid 2005;15:432-438. [PubMed: 15929664]

30. Zhang P, Zuo H, Ozaki T, Nakagomi N, Kakudo K. Cancer stem cell hypothesis in thyroid cancer. Pathol Int 2006;56:485-489. [PubMed: 16930327]

31. Mitsutake N, Iwao A, Nagai K, Namba H, Ohtsuru A, Saenko V, Yamashita S. Characterization of side population in thyroid cancer cell lines: cancer stem-like cells are enriched partly but not exclusively. Endocrinology 2007;148:1797-1803. [PubMed: 17234707]

32. Patrawala L, Calhoun T, Schneider-Broussard R, Zhou J, Claypool K, Tang DG. Side population is enriched in tumorigenic, stem-like cancer cells, whereas ABCG2+ and ABCG2- cancer cells are similarly tumorigenic. Cancer Res 2005;65:6207-6219. [PubMed: 16024622]

33. Chiba T, Kita K, Zheng YW, Yokosuka O, Saisho H, Iwama A, Nakauchi H, Taniguchi H. Side population purified from hepatocellular carcinoma cells harbors cancer stem cell-like properties. Hepatology 2006;44:240-251. [PubMed: 16799977]

34. Kondo T, Setoguchi T, Taga T. Persistence of a small subpopulation of cancer stem-like cells in the C6 glioma cell line. Proc Natl Acad Sci USA 2004;101:781-786. [PubMed: 14711994]

35. Cameselle-Teijeiro J, Febles-Perez C, Sobrinho-Simoes M. Papillary and mucoepidermoid carcinoma of the thyroid with anaplastic transformation: a case report with histologic and immunohistochemical findings that support a provocative histogenetic hypothesis. Pathol Res Pract 1995;191:1214-1221. [PubMed: 8927569]

36. Burstein DE, Nagi C, Wang BY, Unger P. Immunohistochemical detection of p53 homolog p63 in solid cell nests, papillary thyroid carcinoma, and hashimoto's thyroiditis: A stem cell hypothesis of papillary carcinoma oncogenesis. Hum Pathol 2004;35:465-473. [PubMed: 15116328]

37. Yang A, McKeon F. P63 and P73: P53 mimics, menaces and more. Nat Rev Mol Cell Biol 2000;1:199-207. [PubMed: 11252895] 
38. Pellegrini G, Dellambra E, Golisano O, Martinelli E, Fantozzi I, Bondanza S, Ponzin D, McKeon F, De Luca M. p63 identifies keratinocyte stem cells. Proc Natl Acad Sci USA 2001;98:3156-3161. [PubMed: 11248048] 